Jurnal Indonesia Sosial Teknologi:p-ISSN: 2723 - 6609

e-ISSN :2745-5254

Vol. 3, No.1 Januari 2022

\title{
ANALISIS APLIKASI MFIN TERHADAP KEPUASAN KARYAWAN PT.MANDALA MULTIFINANCE, TBK DENGAN FRAMEWORK CUSTOMER SATISFACTION INDEX (CSI)
}

\author{
Abdul Rahmadan Haeradi ${ }^{1}$, Adi Hermawansyah ${ }^{2}$, Nuorma Wahyuni ${ }^{3}$ \\ STMIK Borneo Internasional ${ }^{123}$ \\ Email: abdul_rahmadan.17@stmik-borneo.ac.id ${ }^{1}$, adi.hermawansyah@stmik- \\ borneo.ac.id ${ }^{2}$, nuorma.wahyuni@stmik-borneo.ac.id ${ }^{3}$.
}

\begin{abstract}
Abstrak
Aplikasi MFIN memiliki dampak yang luas dalam pekerjaan sehari-hari mereka untuk membuatnya lebih mudah bagi perwakilan, mengingat efek samping dari persepsi awal pada aplikasi MFIN, tanda masalah dalam aplikasi MFIN adalah masih mengalami kesalahan, penyegaran program tidak memiliki manual, sehingga kesalahan sering terjadi. Sehingga penting untuk mengkaji pemenuhan representatif dengan aplikasi MFIN. Kajian ini bermaksud untuk menginvestigasi penerapan MFIN pada pemenuhan tenaga kerja di PT. Mandala Multifinance, Tbk. Eksplorasi ini diarahkan pada beberapa cabang dan contoh dalam review ini adalah perwakilan dari PT. Mandala Multifinance, Tbk. Strategi yang digunakan dalam review ini adalah Consumer loyalty File (CSI). Melihat dampak dari penanganan dan pemeriksaan informasi yang telah dilakukan, cenderung disimpulkan bahwa laporan atau permasalahan yang ada di PT. Mandala Multifinance, Tbk terhadap aplikasi MFIN, tidak semuanya benar berdasarkan hasil penanganan informasi yang telah diselesaikan ada kepentingan atau asumsi dengan klasifikasi yang sangat terpenuhi, dapat kita ketahui dari nilai CSI didapatkan angka 86,76\% tergantung pada tabel File CSI didelegasikan umumnya sangat baik. Ini menyiratkan bahwa sebagian besar pekerja sangat senang dengan aplikasi MFIN.
\end{abstract}

Kata kunci: Analisis Kepuasan, Customer Satisfaction Index (CSI), Aplikasi MFIN

\section{Abstract}

The MFIN application has an extensive impact in their day by day work to make it more straightforward for representatives, in view of the aftereffects of starting perceptions on the MFIN application, a sign of issues in the MFIN application is as yet encountering blunders, program refreshes don't have a manual, so mistakes regularly happen. So it is important to examine representative fulfillment with the MFIN application. This review means to investigate the MFIN application on worker fulfillment at PT. Mandala Multifinance, Tbk. This exploration was directed in a few branches and the example in this review were representatives of PT. Mandala Multifinance, Tbk. The strategy utilized in this review is the Consumer loyalty File (CSI). In light of the aftereffects of information handling and examination that has been done, it tends to be inferred that the reports or issues that exist in PT. Mandala Multifinance, Tbk to the MFIN application, not every one of them are right founded on the aftereffects of information handling that has been completed there is an 
Abdul Rahmadan Haeradi, Adi Hermawansyah, Nuorma Wahyuni.

interest or assumption with an exceptionally fulfilled classification, we can know from the CSI esteem got a figure of $86.76 \%$ dependent on the CSI File table is delegated generally excellent. This implies that most workers are extremely happy with the MFIN application.

Keywords: Satisfaction Analysis, Customer Satisfaction Index (CSI), Application MFIN.

\section{Pendahuluan}

PT. Mandala Multifinance, Tbk adalah organisasi keuangan yang bergerak di bidang administrasi pembiayaan multiguna. PT. Mandala Multifinance, Tbk adalah sebuah organisasi persewaan berdasarkan Surat Keputusan Pendeta Uang Republik Indonesia No. 323/KMK.017/1997 pada tanggal 21 Juni 1997 bahwa kegiatan usaha organisasi tersebut termasuk persewaan (Sarwindah, 2020). Organisasi ini menawarkan beberapa jenis bantuan termasuk pembiayaan ventura, pembiayaan modal kerja, pembiayaan multiguna dan latihan bisnis pembiayaan lainnya yang bergantung pada Otoritas Administrasi Moneter (OJK). Baru-baru ini, organisasi ini berpusat pada pembiayaan pelanggan, pembiayaan untuk kendaraan roda dua, perangkat keras dan furnitur, organisasi miniatur dan kendaraan. Organisasi memiliki mimpi dan misi untuk menawarkan dukungan terbaik kepada pembeli dan kolega.

Pendorong dalam inovasi data dan korespondensi yang ada saat ini adalah menyesuaikan sikap dan cara kerja di dalam suatu organisasi, dengan memperluas kebutuhan akan inovasi data yang dapat memberikan keuntungan dan irisan waktu bagi suatu organisasi (Marpaung, 2018). Proses bisnis merupakan variabel pendorong pentingnya inovasi data (Nasution, 2014). Kebutuhan administrasi inovasi data saat ini merupakan salah satu cara untuk menjawab kebutuhan suatu organisasi. Kerangka yang ada saat ini dikhawatirkan akan menghambat presentasi perwakilan dan pengurus di dalamnya. Hal ini karena inovasi data tidak hanya mencakup inovasi yang digunakan dalam suatu organisasi, tetapi juga mencakup siklus-siklus yang ada di dalamnya secara utuh.

PT.Mandala Multifinance, Tbk memberikan dukungan operasional dengan mencoba memberikan solusi berupa aplikasi MFIN berbasis web. Aplikasi ini diharapkan dapat menunjang kegiatan operasional kantor karena memberikan pelayanan input data nasabah, find kosumen, input dan hapus denda, info data karyawan, input dan cetak kwitansi dan masih banyak fungsi lainnya (Ogi, Pangemanan, \& Pontoh, 2020). Aplikasi MFIN memiliki beberapa kriteria untuk menginput data nasabah seperti identitas konsumen kartu tanda penduduk (KTP), kartu keluarga (KK), bukti kepemilikan rumah dan keterangan penghasilan berupa slip gaji (Sarwindah, 2020).

Aplikasi MFIN memiliki pengaruh yang cukup besar dalam pekerjaan sehari-hari untuk mempermudah setiap kegiatan karyawan, dikarenakan aplikasi MFIN merupakan aplikasi layanan karyawan yang dapat diakses secara mandiri. Namun berdasarkan hasil observasi awal pada aplikasi MFIN didapatkan indikasi masalah bawa pada aplikasi MFIN masih mengalami error, update program yang tidak memiliki manual book sebagai 
petunjuk penggunaan aplikasi, aplikasi MFIN hanya dapat diakses hanya melalui dekstop perushaan saja, sehingga sering kali terjadi kesalahan dalam penggunaan aplikasi MFIN.

Berdasarkan latar belakang diatas maka menurut peneliti penelitian ini layak untuk dilakukan analisis kepuasan menggunakan metode Customer Satisfaction Index (CSI). Guna mempertimbangkan tingkat kepentingan dari kualitas Pelayanan yang diukur (Hadining, 2020). Harapan setelah melakukan analisis kepuasan karyawan terhadap aplikasi MFIN PT. Mandala Multifinance,Tbk mengunakan metode Customer Satisfaction Index (CSI) dapat menjadi pertimbangan bagi perusahaan untuk meningkatkan pelayanan yang maksimal terhadap karyawan yang juga nantinya akan berpengaruh terhadap pelayanan kepada nasabah.

\section{Metode Penelitian}

Analisis data dilakukan setelah data-data terkumpul anaslisa yang akan dilakukan pada penelitian ini ialah analisa kepuasan karyawan terhadap aplikasi MFIN untuk mendapatkan kepuasan karyawan tersebut menggunakan metode Customer Satisfaction Index (CSI).

Customer Satisfaction Index (CSI) adalah metode untuk menentukan tingkat pemenuhan klien yang memanfaatkan bantuan secara umum dengan memeriksa tingkat signifikansi sifat barang atau administrasi. Model selanjutnya mengembangkan kualitas bantuan, menilai pelaksanaan perwakilan dan memberikan penghargaan sebagai garis besar yang membahas tingkat loyalitas konsumen. CSI merupakan pengujian kuantitatif sebagai tingkat kepuasan klien dalam studi loyalitas konsumen (Widodo \& Sutopo, 2018).

Jadi CSI adalah daftar untuk menentukan tingkat umum loyalitas konsumen dengan metodologi yang memikirkan pentingnya kualitas yang disengaja.

Strategi CSI menikmati keuntungan menjadi mahir (catatan pemenuhan serta memperoleh data yang diidentifikasi dengan aspek/anggapan yang harus ditingkatkan), mudah digunakan dan lugas, memanfaatkan skala yang memiliki pengaruh tinggi dan kualitas tak tergoyahkan. CSI memberikan informasi yang jelas tentang loyalitas konsumen yang adil dan merata sehingga penilaian berkala dapat diselesaikan untuk lebih mengembangkan kualitas administrasi (Widodo \& Sutopo, 2018).

Perhitungan menggunakan metode CSI diilustrasikan pada tabel 1:

Tabel 1

Tabel Jawaban Responden

\begin{tabular}{lllll}
\hline \multirow{2}{*}{ No } & \multirow{2}{*}{ Atribut } & Rata-rata & & $\begin{array}{l}\text { Skor }(\mathrm{S}) \\
=\mathrm{I} x \mathrm{P}\end{array}$ \\
& & Importance $(\mathrm{I})$ & Performance $(\mathrm{P})$ & \\
\hline 1 & $\ldots \ldots \ldots \ldots \ldots$ & (skala 1-5) & (skala 1-5) & \\
\hline 3 & $\ldots \ldots \ldots \ldots \ldots$ & & \\
\hline & $\ldots \ldots \ldots \ldots \ldots$ & & Total $(\mathrm{S})=\mathrm{T}$ \\
\hline
\end{tabular}


Abdul Rahmadan Haeradi, Adi Hermawansyah, Nuorma Wahyuni.

Perhitungan umum CSI adalah bahwa nilai normal pada segmen minat (I) adalah untuk memperoleh Y dan hasil dari (I) dan (P) pada bagian skor (S) adalah untuk mendapatkan T. Jadi resepnya diperoleh seperti dalam kondisi berikut:

1. Menentukan Mean Importance Score (MIS) dan Mean Satisfaction Score (MSS) Mean Importance Score (MIS) adalah rata-rata dari skor kepentingan suatu atribut. Sedangkan Mean Satisfaction Score (MSS) adalah rata-rata skor untuk tingkat kepuasan yang berasal dari kinerja jasa yang dirasakan oleh pelanggan.

$M I S=\frac{\sum_{i=1}^{n} \mathrm{yi}}{n}$ (Rumus 3)

Keterangan :

$y i=$ Nilai kepentingan atribut y ke-i

$n=$ Jumlah responden

$M S S=\frac{\sum_{i=1}^{n} \mathrm{yi}}{n}$. .(Rumus 4)

Keterangan :

$y i=$ Nilai kepentingan atribut y ke-i

$n=$ Jumlah responden

2. Menghitung Weight Factor (WF) atau faktor tertimbang. Bobot ini merupakan persentase nilai MIS per indikator terhadap total total MIS seluruh indikator.

$W F=\frac{M I S i}{\sum_{i=1}^{p} M I S i} \times 100 \%$ .(Rumus 5)

Keterangan :

MISi = Nilai rata-rata kepentingan ke-i

$\sum_{i}^{p} M I S i=$ Total rata-rata kepentingan dari ke-i ke-p

3. Menghitung Weight Score (WS) atau skor tertimbang. Bobot ini merupakan perkalian antara WF dengan rata-rata tingkat kepuasan.

$\mathrm{WSi}=\mathrm{WFi} \times \mathrm{MSS}$ (Rumus 6)

WFi $=$ Faktor tertimbang ke-i

MPS = Rata-rata tingkat kepentingan

4. Menentukan Customer Satisfaction Index (CSI)

$C S I=\frac{T}{5 Y} \times 100 \%$ ..(Rumus 7)

Keterangan:

CSI = Customer Satisfaction Index

$\mathrm{T}=$ Total hasil kali (I) dengan $(\mathrm{P})$

$\mathrm{Y}=$ Total nilai rata-rata kolom I

Nilai lima pada $5 Y$ adalah nilai paling ekstrim pada skala estimasi. Skala estimasi yang digunakan dalam tinjauan ini adalah Skala Likert yang terdiri dari lima level. 
Penggunaan ukuran 5, 7 dan 10 memiliki daftar keunggulan kualitas yang tak tergoyahkan, legitimasi dan kekuatan pemisahan daripada ukuran 2, 3, dan 4. Timbangan 5, 7 dan 10 lebih sederhana untuk dijawab, sedangkan skala 2, 3, dan 4 sangat cepat namun tidak menjawab jawaban responden. . Rata-rata yang sama diperoleh ketika skala 5 dan 7 diskalakan ulang. Jumlah ukuran 5 dan 7 setara, namun tidak dapat mengukur hingga ukuran 10 karena normal 5 dan 7 menghasilkan normal yang lebih tinggi (Khusna, 2020).

Skala pengukuran untuk Importance ditunjukkan pada tabel 2. Sedangkan skala pengukuan untuk Performance ditunjukkan pada tabel 3.

Tabel 2 Skala pengukuran Importance

\begin{tabular}{lc}
\hline Variabel Importance (I) & Skor \\
\hline Sangat Penting & 5 \\
\hline Penting & 4 \\
\hline Cukup Penting & 3 \\
\hline Kurang Penting & 2 \\
\hline Tidak Penting & 1 \\
\hline
\end{tabular}

Tabel 3 Skala pengukuran Performance

\begin{tabular}{lc}
\hline Variabel Performance $(\mathrm{P})$ & Skor \\
\hline Sangat Puas & 5 \\
\hline Puas & 4 \\
\hline Cukup Puas & 3 \\
\hline Kurang Puas & 2 \\
\hline Tidak Puas & 1 \\
\hline
\end{tabular}

Data kategori nilai CSI dimulai dari nilai terkecil yaitu 0\% hingga nilai terbesar yaitu $100 \%$. Untuk menentukan kelas interval hal yang pertama dilakukan yaitu mencari nilai rentang seperti pada persamaan berikut (Khusna, 2020):

Rentang $=$ Data terbesar - Data Terkecil

Rentang $=100-0=100$

Selanjutnya banyaknya kelas interval yang diperlukan yaitu sebanyak 5 kelas. Untuk menentukan panjang kelas interval (p) maka digunakan persamaan berikut :

$\mathrm{p}=\frac{\text { rentang }}{\text { banyak kelas }}$ ..(Rumus 7)

$\mathrm{p}=\frac{100}{5}=20$

Maka diperoleh kelas rentang klasifikasi CSI seperti yang terlihat pada tabel 4. Secara umum, dengan asumsi nilai CSI di atas setengah, dapat dikatakan bahwa klien bantuan sangat terpenuhi, tetapi jika harga CSI di bawah setengah, klien administrasi tidak terpenuhi. Penghargaan CSI dalam tinjauan ini dipisahkan menjadi lima standar dari kecewa hingga sangat terpenuhi. 
Abdul Rahmadan Haeradi, Adi Hermawansyah, Nuorma Wahyuni.

Tabel 4 Nilai Kategori CSI

\begin{tabular}{lll}
\hline No & Nilai CSI & Kategori CSI \\
\hline 1 & $0 \%-20 \%$ & Tidak Puas \\
\hline 2 & $21 \%-40 \%$ & Kurang Puas \\
\hline 3 & $41 \%-60 \%$ & Cukup Puas \\
\hline 4 & $61 \%-80 \%$ & Puas \\
\hline 5 & $81 \%-100 \%$ & Sangat Puas \\
\hline
\end{tabular}

Pada umumnya, dengan asumsi nilai CSI di atas 50\%, dapat dikatakan bahwa klien bantuan terpenuhi, tetapi jika harga CSI di bawah 50\%, klien administrasi tidak seharusnya terpenuhi. Nilai CSI dalam ulasan ini diisolasi menjadi lima model dari kecewa hingga sangat terpenuhi seperti yang ditampilkan pada Tabel 2.6. Setelah mendapatkan nilai, kita hanya perlu membandingkan nilainya dengan tabel di atas (Budianto, 2013). Jadi sangat mungkin tertutup seberapa besar loyalitas konsumen dengan administrasi yang diberikan.

\section{Metode Pengumpulan Data}

Dalam tinjauan ini, prosedur pemilihan informasi diselesaikan untuk memperoleh informasi yang dibutuhkan para ilmuwan dan dapat diterapkan pada perincian masalah tinjauan (Dr. Wahidpure 2017). Dalam penelitian, prosedur pemilihan informasi adalah cara yang paling esensial, alasan utama penelitian adalah untuk mendapatkan informasi. Strategi pemilahan informasi diperlukan untuk mendapatkan standar informasi yang ideal. Strategi bermacam-macam informasi meliputi:

1. Penelitian Kepustakaan (Library Research)

a. Studi pustaka

Studi menulis adalah prosedur pengumpulan informasi yang dapat dilakukan dengan mensurvei buku-buku tulisan, catatan, dan laporan yang ada yang mengidentifikasi dengan masalah yang akan diselesaikan. Berkonsentrasi pada tulisan yang diidentifikasi dengan masalah yang diteliti untuk dijadikan hipotesis relatif (Darmalaksana, 2020).

b. Studi literatur

Bermacam-macam penelitian penulisan ini adalah sebagai ujian masa lalu yang dapat digunakan sebagai aturan dan korelasi. Kajian penulisan ini dapat menjadi referensi hipotetis yang relevan dengan situasi atau masalah yang ditemukan. Efek samping dari studi penulisan adalah bermacam-macam referensi yang berlaku untuk definisi masalah (Jamaludin, 2017).

2. Penelitian Lapangan(Field Research)

Kuisioner merupakan strategi pengumpulan informasi berupa pertanyaan tersusun yang digunakan untuk mengumpulkan informasi sebagai data dari responden tentang pemenuhan aplikasi MFIN (Wulandari, Yamardi, dan Rohayatin 2020). 
Penyebaran survei dalam ulasan ini dipimpin melalui struktur google dengan koneksi http://bit.ly/Radi17. Dalam review ini, responden adalah pekerja PT. Mandala Multifinance.

\section{Sumber Data}

Pengumpulan data dilakukan agar dapat memecahkan suatu permasalahan yang ada sehingga data yang diberikan akurat. Dalam penelitian ilmiah, metode pengumpulan data dapat dilakukan dengan cara sebagai berikut:

1. Data Primer

Data primer ialah data yang diperoleh melalui sumber asli atau sumber pertama data tersebut diperoleh (Hua, 2016). Pada penelitian ini, data primer diperoleh melalui google from dengan link http://bit.ly/Radi17 kepada karyawan PT.Mandala Multifinance untuk mengukur kepuasan karyawan tersebut dalam menggunakan aplikasi MFIN, survei kepuasan menggunakan kuesioner terhadap karyawan PT.Mandala Multifinance di beberapa cabang di antaranya : cabang grogot, cabang balikpapan, cabang penajam, cabang tanjung, cabang tengarong, dan cabang berau,

2. Data Sekunder

Informasi tambahan yang diperoleh atau dikumpulkan oleh para ahli dari sumber-sumber penelitian sebelumnya, seperti catatan, tulisan, buku, informasi investigasi pemenuhan dan referensi yang didapat dari PT. Profil organisasi Mandala Multifinance, teknik kerja, strategi kerja, SOP (Standard Functional System), dan sudut pandang ekologi serta informasi pendukung lainnya (Martono, 2010). Juga, penelitian menulis kualitas administrasi, loyalitas konsumen administrasi dan pemahaman Daftar loyalitas Konsumen (CSI) yang diidentifikasi dengan pemenuhan pekerja dikumpulkan untuk membantu memastikan nilai Signifikansi dan Kinerja.

\section{Hasil dan Pembahasan}

Berikut tahapan penanganan informasi signifikansi dan eksekusi dalam mengestimasi tingkat pemenuhan representatif pada PT. Mandala Multifinance dengan membuat Consumer loyalty File (CSI), CSI digunakan untuk menentukan tingkat loyalitas konsumen secara umum dengan melihat tingkat signifikansinya.

Menentukan Mean Importance Score (MIS) dan Mean Satisfaction Score (MSS) Mean Importance Score (MIS) adalah rata-rata dari skor kepentingan suatu atribut. Sedangkan Mean Satisfaction Score (MSS) adalah rata-rata skor untuk tingkat kepuasan yang berasal dari kinerja jasa yang dirasakan oleh pelanggan.

$M I S=\frac{\sum_{i=1}^{n} \mathrm{yi}}{n}$ (Rumus 8)

Keterangan :

$y i=$ Nilai kepentingan atribut y ke-i

$n=$ Jumlah responden 
Abdul Rahmadan Haeradi, Adi Hermawansyah, Nuorma Wahyuni.

Perhitungan nilai MIS y ke-i :

$M I S=\frac{4+5+5+4 \ldots \ldots \ldots+5}{100}=4,66$

Rata-rata hasil keseluruhan nilai kepentingan dan kepuasan tiap variabel dapat dilihat pada tabel berikut :

$M S S=\frac{\sum_{i=1}^{n} \mathrm{yi}}{n}$. .(Rumus 9)

Keterangan :

$y i=$ Nilai kepentingan atribut y ke-i

$n=$ Jumlah responden

Perhitungan nilai MIS y ke-i :

$M S S=\frac{4+4+5+4 \ldots \ldots \ldots+4}{100}=4,33$

Rata-rata hasil keseluruhan nilai kepentingan dan kepuasan tiap variabel dapat dilihat pada tabel berikut :

Tabel 5 Rekapitulasi nilai MIS dan MSS

\begin{tabular}{|c|c|c|c|c|}
\hline & $\begin{array}{l}\text { Total } \\
\text { tance }\end{array}$ & MIS & $\begin{array}{l}\text { Total } \\
\text { mance }\end{array}$ & MSS \\
\hline 1 & 466 & 4,66 & 433 & 4,33 \\
\hline 2 & 458 & 4,58 & 437 & 4,37 \\
\hline 3 & 456 & 4,56 & 435 & 4,35 \\
\hline 4 & 458 & 4,58 & 434 & 4,34 \\
\hline 5 & 451 & 4,51 & 430 & 4,30 \\
\hline 6 & 451 & 4,51 & 429 & 4,29 \\
\hline 7 & 437 & 4,37 & 426 & 4,26 \\
\hline 8 & 459 & 4,59 & 448 & 4,48 \\
\hline 9 & 464 & 4,64 & 446 & 4,46 \\
\hline 10 & 462 & 4,62 & 434 & 4,34 \\
\hline 11 & 458 & 4,58 & 441 & 4,41 \\
\hline 12 & 462 & 4,62 & 434 & 4,34 \\
\hline 13 & 440 & 4,40 & 379 & 3,79 \\
\hline 14 & 458 & 4,58 & 435 & 4,35 \\
\hline 15 & 458 & 4,58 & 432 & 4,32 \\
\hline 16 & 458 & 4,58 & 415 & 4,15 \\
\hline 17 & 458 & 4,58 & 445 & 4,45 \\
\hline 18 & 459 & 4,59 & 432 & 4,32 \\
\hline 19 & 468 & 4,68 & 442 & 4,42 \\
\hline 20 & 462 & 4,62 & 442 & 4,42 \\
\hline 21 & 460 & 4,60 & 439 & 4,39 \\
\hline 22 & 457 & 4,57 & 439 & 4,39 \\
\hline
\end{tabular}


Analisis Aplikasi MFIN Terhadap Kepuasan Karyawan Pt.Mandala Multifinance, TBK Dengan Framework Customer Satisfaction Index (CSI)

\begin{tabular}{lllll}
\hline 23 & 456 & 4,56 & 428 & 4,28 \\
\hline 24 & 460 & 4,60 & 442 & 4,42 \\
\hline 25 & 457 & 4,57 & 445 & 4,45 \\
\hline Total & & 114,33 & & 108,42 \\
\hline
\end{tabular}

1. Menghitung Weight Factor (WF) atau faktor tertimbang. Bobot ini merupakan persentase nilai MIS per indikator terhadap total total MIS seluruh indikator.

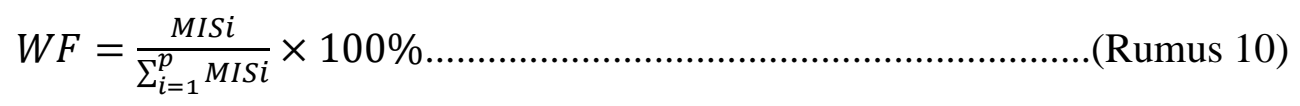

Keterangan :

MISi = Nilai rata-rata kepentingan ke-i

$\sum_{i}^{p} M I S i=$ Total rata-rata kepentingan dari ke-i ke-p

Perhitungan Nilai WF :

$$
W F=\frac{4,66}{4,66+4,58+4,56+4,58 \ldots \ldots \ldots+4,57} \times 100 \%
$$

$W F=4,08 \%$

Berikut adalah rekapitulasi hasil perhitungan nilai Weight Factors (WF):

Tabel 6 Rekapitulasi Nilai MIS dan WF

\begin{tabular}{|c|c|c|}
\hline No & MIS & Nilai WF $(\%)$ \\
\hline 1 & 4,66 & 4,08 \\
\hline 2 & 4,58 & 4,01 \\
\hline 3 & 4,56 & 3,99 \\
\hline 4 & 4,58 & 4,01 \\
\hline 5 & 4,51 & 3,94 \\
\hline 6 & 4,51 & 3,94 \\
\hline 7 & 4,37 & 3,82 \\
\hline 8 & 4,59 & 4,01 \\
\hline 9 & 4,64 & 4,06 \\
\hline 10 & 4,62 & 4,04 \\
\hline 11 & 4,58 & 4,01 \\
\hline 12 & 4,62 & 4,04 \\
\hline 13 & 4,40 & 3,85 \\
\hline 14 & 4,58 & 4,01 \\
\hline 15 & 4,58 & 4,01 \\
\hline 16 & 4,58 & 4,01 \\
\hline 17 & 4,58 & 4,01 \\
\hline 18 & 4,59 & 4,01 \\
\hline 19 & 4,68 & 4,09 \\
\hline 20 & 4,62 & 4,04 \\
\hline 21 & 4,60 & 4,02 \\
\hline & & \\
\hline
\end{tabular}


Abdul Rahmadan Haeradi, Adi Hermawansyah, Nuorma Wahyuni.

\begin{tabular}{|c|c|c|}
\hline 22 & 4,57 & 4,00 \\
\hline 23 & 4,56 & 3,99 \\
\hline 24 & 4,60 & 4,02 \\
\hline 25 & 4,57 & 4,00 \\
\hline \multicolumn{2}{|c|}{ Total } & $100 \%$ \\
\hline
\end{tabular}

2. Menghitung Weight Score (WS) atau skor tertimbang. Bobot ini merupakan perkalian antara WF dengan rata-rata tingkat kepuasan.

$\mathrm{WSi}=\mathrm{WFi} \times \mathrm{MSS}$

(Rumus 11)

WFi $=$ Faktor tertimbang ke-i

MPS = Rata-rata tingkat kepentingan

Perhitungan Nilai WSi :

$W S_{1}=4,08 \% \times 4,66$

$W S_{1}=0,176$

Berikut adalah rekapitulasi hasil perhitungan Weight Score (WS) :

Tabel 7 Rekapitulasi Nilai WS

\begin{tabular}{|c|c|c|c|}
\hline No & Nilai WF (\%) & MSS & Nilai WS \\
\hline 1 & 4,08 & 4,33 & 0,176 \\
\hline 2 & 4,01 & 4,37 & 0,175 \\
\hline 3 & 3,99 & 4,35 & 0,173 \\
\hline 4 & 4,01 & 4,34 & 0,174 \\
\hline 5 & 3,94 & 4,30 & 0,170 \\
\hline 6 & 3,94 & 4,29 & 0,169 \\
\hline 7 & 3,82 & 4,26 & 0,163 \\
\hline 8 & 4,01 & 4,48 & 0,180 \\
\hline 9 & 4,06 & 4,46 & 0,181 \\
\hline 10 & 4,04 & 4,34 & 0,175 \\
\hline 11 & 4,01 & 4,41 & 0,177 \\
\hline 12 & 4,04 & 4,34 & 0,175 \\
\hline 13 & 3,85 & 3,79 & 0,146 \\
\hline 14 & 4,01 & 4,35 & 0,174 \\
\hline 15 & 4,01 & 4,32 & 0,173 \\
\hline 16 & 4,01 & 4,15 & 0,166 \\
\hline 17 & 4,01 & 4,45 & 0,178 \\
\hline 19 & 4,09 & 4,42 & 0,181 \\
\hline 20 & 4,04 & 4,42 & 0,179 \\
\hline 21 & 4,02 & 4,39 & 0,177 \\
\hline 22 & 4,00 & 4,39 & 0,175 \\
\hline
\end{tabular}




\begin{tabular}{|l|l|l|l|}
\hline 18 & 4,01 & 4,32 & 0,173 \\
\hline 23 & 3,99 & 4,28 & 0,171 \\
\hline 24 & 4,02 & 4,42 & 0,178 \\
\hline 25 & 4,00 & 4,45 & 0,178 \\
\hline \multicolumn{2}{|c|}{ Total } \\
\hline
\end{tabular}

3. Menentukan Customer Satisfaction Index (CSI)

$C S I=\frac{T}{5 Y} \times 100 \%$ (Rumus 12)

Keterangan:

CSI = Customer Satisfaction Index

$\mathrm{T} \quad=$ Total hasil kali $(\mathrm{I})$ dengan $(\mathrm{P})$

$\mathrm{Y}=$ Total nilai rata-rata kolom I

Nilai persentase CSI dihitung dengan membagi skor tertimbang dengan skala maksimum yang digunakan jadi perhitungannya adalah :

$C S I=\frac{4,338}{5} \times 100 \%$

$C S I=86,76 \%$

\section{Hasil Uji Data}

Analisa Univariat ini digunakan untuk menjelaskan atau mendeskripsikan angka/nilai karakteristik responden memilih apalikasi e-Yankel. Dengan perhitungan umum, penentuan besarnya presentase sebagai:

Hasil Koesioner adalah :

\section{Tabel 12 Validitas Peryataan}

\begin{tabular}{lllll}
\hline & Ite & & & \multicolumn{1}{l}{ Keteranga } \\
Peryataan & m & r Tabel & r Hitung & n \\
\hline Manajemen Layanan sebagai sebuah & & 0.03703703 & 3.703703 & \\
praktek & P3 & 7 & 7 & Valid \\
& & 0.04481481 & 2.911111 & \\
& P7 & 5 & 1 & Valid \\
\hline \multirow{2}{*}{ Prinsip-prinsip Service Operation } & & 0.03851851 & 3.570370 & \\
& P1 & 9 & 4 & Valid \\
& & 0.04111111 & 3.307407 & \\
& P2 & 1 & 4 & Valid \\
Proses-proses Service Operation & & 0.03703703 & 3.703703 & \\
& P6 & 7 & 7 & Valid \\
& & 0.04629629 & 2.911111 & \\
& P8 & 6 & 1 & Valid \\
\cline { 2 - 3 } & & & &
\end{tabular}


Abdul Rahmadan Haeradi, Adi Hermawansyah, Nuorma Wahyuni.

\begin{tabular}{|c|c|c|c|c|}
\hline $\begin{array}{l}\text { Aktivitas-aktivitas Service Operation } \\
\text { Umum }\end{array}$ & P5 & $\begin{array}{l}0.06333333 \\
3\end{array}$ & $\begin{array}{l}2.911111 \\
1\end{array}$ & Valid \\
\hline Pengorganisasian Service Operation & P9 & $\begin{array}{l}0.03851851 \\
9\end{array}$ & $\begin{array}{l}3.570370 \\
4\end{array}$ & Valid \\
\hline $\begin{array}{lll}\text { Konsiderasi } & \text { Teknologi } & \text { Service } \\
\text { Operation } & & \\
\end{array}$ & P4 & 0.05037037 & $\begin{array}{l}2.381481 \\
5\end{array}$ & Valid \\
\hline $\begin{array}{l}\text { Mengimplementasikan } \quad \text { Service } \\
\text { Operation }\end{array}$ & P10 & 0.03962963 & $\begin{array}{l}3.440740 \\
7\end{array}$ & Valid \\
\hline
\end{tabular}

Adapun hasil uji validitas sebagai berikut :

a. Manajemen layanan sebagai sebuah praktek P3 r T =0,037, $\mathrm{r} \mathrm{H}=3.70$ dan P7 r T $=0.044, \mathrm{r} \mathrm{H}=2,91$ adalah valid

b. Prinsip-prinsip Service Operation P1 r T = 0,038, r H = 3,57 dan P2 r T = 0,041 , $\mathrm{r} \mathrm{H}=3,307$ adalah valid

c. Proses-proses Service Operation P6 r T = 0,037, $\mathrm{r} \mathrm{H}=3,703$ dan P8 r T = 0,046, r $\mathrm{H}=2,91$ adalah valid

d. Aktivitas-aktivitas Service Operation Umum P5 r T =0,063, r H = 2,91 adalah valid

e. Pengorganisasian Service Operation Service Operation P9 r T = 0,038, r H = 3,57 adalah valid

f. Konsiderasi Teknologi Service Operation P4 r T =0,050, $\mathrm{r} \mathrm{H}=2,381$ adalah valid

g. Mengimplementasian Service Operation P10 r T $=0,039$, r H $=\mathbf{3 , 4 4 0}$ adalah valid

Tabel 13 Bobot Nilai 


\begin{tabular}{|c|c|c|c|c|c|c|c|c|c|c|}
\hline \multicolumn{11}{|c|}{ Bobot Nilai } \\
\hline Sub Domain & 0 & 1 & 2 & 3 & Total Bobot & \multicolumn{3}{|c|}{ Maturity Level } & T Bobot & $\mathrm{Jmh} \mathrm{ML}$ \\
\hline \multicolumn{11}{|l|}{ Service management as a Practise } \\
\hline P3 & 0 & 28 & 0 & 6 & 34 & 29.96 & 0 & 6.09 & 36.89 & 36.05 \\
\hline P7 & 0 & 22 & 6 & 6 & 34 & 23.21 & 6.09 & 6.09 & 36.89 & 35.39 \\
\hline \multicolumn{11}{|l|}{ Service Operation Principles } \\
\hline P1 & 0 & 18 & 1 & 6 & 34 & 18.81 & 1.003 & 6.09 & 36.89 & 25.9 \\
\hline P2 & 0 & 25 & 3 & 6 & 34 & 26.563 & 3.023 & 6.09 & 36.89 & 35.68 \\
\hline \multicolumn{11}{|l|}{ Service Operation Processes } \\
\hline P6 & 0 & 28 & 0 & 6 & 34 & 29.96 & 0 & 6.09 & 36.89 & 36.05 \\
\hline P8 & 0 & 22 & 5 & 1 & 34 & 23.21 & 5.063 & 1.003 & 36.89 & 29.28 \\
\hline \multicolumn{11}{|l|}{ Service Operation Common Operation Activities } \\
\hline P5 & 0 & 8 & 20 & 6 & 34 & 8.16 & 21 & 6.09 & 36.89 & 35.25 \\
\hline \multicolumn{11}{|l|}{ Organising Service Operation } \\
\hline P9 & 0 & 21 & 1 & 6 & 34 & 22.103 & 1.003 & 6.09 & 36.89 & 29.2 \\
\hline \multicolumn{11}{|l|}{ Service Operation Technology Conciderations } \\
\hline P4 & 0 & 18 & 10 & 6 & 34 & 18.81 & 10.25 & 6.09 & 36.89 & 35.15 \\
\hline \multicolumn{11}{|l|}{ Implementating Service Operation } \\
\hline P10 & 0 & 26 & 2 & 6 & 34 & 27.69 & 2.01 & 6.09 & 36.89 & 35.79 \\
\hline
\end{tabular}

\section{Pembahasan}

Daftar Loyalitas Konsumen (CSI) digunakan untuk menentukan tingkat loyalitas konsumen secara umum dengan melihat tingkat kepentingan item/administrasi yang dianggap.

$\begin{array}{lll}\text { No } & \text { Nilai CSI } & \text { Kategori CSI } \\ 1 & 0 \%-20 \% & \text { Tidak Puas } \\ 2 & 21 \%-40 \% & \text { Kurang Puas } \\ 3 & 41 \%-60 \% & \text { Cukup Puas } \\ 4 & 61 \%-80 \% & \text { Puas } \\ 5 & 81 \%-100 \% & \text { Sangat Puas }\end{array}$

Pengujian informasi atau information testing dalam review ini menggunakan Consumer Loyalty List (CSI). Pemeriksaan ini digunakan untuk menguji pemenuhan perwakilan di PT. Mandala Multifinance, Tbk untuk memutuskan tingkat pemenuhan atas aplikasi MFIN. Efek samping dari tinjauan ini menunjukkan bahwa perwakilan di PT. Mandala Multifinance, tbk sangat senang dengan adanya aplikasi MFIN, hal ini dibuktikan dengan efek samping dari Consumer loyalty Record (CSI) senilai 86,76\%.

Di mana Catatan Pemenuhan atau Daftar Loyalitas Konsumen (CSI) sangat berharga untuk tujuan internal organisasi. Sebuah model mengamati peningkatan bantuan, dan sebagai gambaran yang membahas tingkat pemenuhan perwakilan secara umum di PT, Mandala Multifinance, Tbk. File loyalitas konsumen CSI digunakan untuk menentukan tingkat pemenuhan pekerja secara umum dengan melihat tingkat kepentingan item/administrasi yang diberikan dalam aplikasi MFIN. File loyalitas konsumen (CSI) sangat membantu untuk tujuan organisasi internal, misalnya memeriksa 
Abdul Rahmadan Haeradi, Adi Hermawansyah, Nuorma Wahyuni.

peningkatan administrasi, sebagai representasi yang membahas tingkat pemenuhan umum klien aplikasi MFIN.

\section{Kesimpulan}

Mengingat penanganan dan penyelidikan informasi yang telah dilakukan, cenderung dianggap sebagai konsekuensi dari persepsi yang mendasari yang telah dibuat, dan isu-isu yang ada di PT. Mandala Multifinance, Tbk untuk aplikasi MFIN, tidak semuanya valid. Bagaimanapun, mengingat efek samping dari penanganan informasi yang telah selesai ada kepentingan atau asumsi dengan klasifikasi yang sangat terpenuhi, kita dapat mengetahui dari nilai CSI yang diperoleh angka $86,76 \%$ tergantung pada tabel Daftar CSI yang didelegasikan secara umum sangat baik dan sisanya $13,24 \%$ pekerja merasa tidak terpenuhi. Ini menyiratkan bahwa sebagian besar pekerja sangat senang dengan aplikasi MFIN saat ini di PT. Mandala Multifinance, Tbk. Bantuan yang diberikan oleh organisasi sangat berpengaruh terhadap latihan-latihan pendampingan yang diberikan kepada klien PT. Mandala Multifinance, Tbk. 
Analisis Aplikasi MFIN Terhadap Kepuasan Karyawan Pt.Mandala Multifinance, TBK Dengan Framework Customer Satisfaction Index (CSI)

\section{Bibliografi}

Budianto, Duwi. (2013). Analisis Kepuasan Konsumen Terhadap Kualitas Pelayanan dan Harga Produk dengan Menggunakan Metode Customer Satisfaction Index (Csi) dan Importance Performance Analysis (Ipa)(Studi Kasus: Minimarket Garuda Pekanbaru). UNIVERSITAS ISLAM NEGERI SULTAN SYARIEF KASIM RIAU.

Darmalaksana, Wahyudin. (2020). Metode Penelitian Kualitatif Studi Pustaka dan Studi Lapangan. Pre-Print Digital Library UIN Sunan Gunung Djati Bandung.

Hadining, Aulia Fashanah. (2020). Analisis Kepuasan Pelanggan Abc Laundry Dengan Menggunakan Metode Service Quality, Importance Performance Analysis (Ipa) Dan Customer Satisfaction Index (Csi). J@ti Undip : Jurnal Teknik Industri, 15(1), 1. https://doi.org/10.14710/jati.15.1.1-10

Hua, Ang Kean. (2016). Pengenalan Rangkakerja Metodologi dalam Kajian Penyelidikan : Satu Kajian Kes Abstrak Introduction to Metodology Framework in Research Study: A Case Study Abstract Pengenalan. Malaysian Journal of Social Sciences and Humanities, 1(2).https://doi.org/10.47405/mjssh.v1i2.8

Jamaludin, Agus. (2017). Pengaruh gaya kepemimpinan terhadap kinerja karyawan pada PT. Kaho Indahcitra Garment Jakarta. JABE (Journal of Applied Business and Economic), 3(3), 161-169.

Khusna, L. (2020). Aplikasi Survei Kepuasan Pelanggan Berbasis Android Menggunakan Metode Customer Satisfaction Index (Csi) Pada Ahass Handayani Semarang.

Marpaung, Junierissa. (2018). Pengaruh Penggunaan Gadget dalam Kehidupan. KOPASTA: Journal of the Counseling Guidance Study Program, 5(2).https://doi.org/10.33373/kop.v5i2.1521

Martono, Nanang. (2010). Metode penelitian kuantitatif: Analisis Isi dan Analisis Data Sekunder (sampel halaman gratis). RajaGrafindo Persada.

Nasution, Muhammad Irwan Padli. (2014). Keunggulan Kompetitif dengan Teknologi Informasi. Jurnal Elektronik.

Ogi, Gratia Patricia, Pangemanan, Sifrid S., \& Pontoh, Winston. (2020). Analisis Pengendalian Intern Atas Penerimaan Kas Pada Pt. Mandala Multifinance, Tbk Cabang Manado. Going Concern: Jurnal Riset Akuntansi, 15(2), 124. https://doi.org/10.32400/gc.15.2.27983.2020

Sarwindah, Marini. (2020). Prototype Sistem Pembiayaan Berbasis MFINWEB pada PT - Mandala Finance Prototype of MFINWEB-Based Financing System at PT . Mandala Finance. 08(4), 322-327. https://doi.org/10.26418/justin.v8i4.41522

Widodo, Sanusi Mulyo, \& Sutopo, Joko. (2018). Metode Customer Satisfaction Index 
Abdul Rahmadan Haeradi, Adi Hermawansyah, Nuorma Wahyuni.

(CSI) untuk mengetahui pola kepuasan pelanggan pada e-commerce model business to customer. Jurnal Informatika Upgris, 4(1). 